\title{
Remote ischemic preconditioning and beyond-are we getting closer to the secret of cardioprotection?
}

\author{
Martina Krüger ${ }^{1}$ (D)
}

Received: 24 September 2019/Revised: 24 September 2019 / Accepted: 26 September 2019/Published online: 21 October 2019

(C) Springer-Verlag GmbH Germany, part of Springer Nature 2019

There is general consensus that the most effective treatment for maintaining cardiac function after coronary occlusion and myocardial ischemia is timely reperfusion of the affected vessels. Unfortunately, reperfusion itself has been associated with further injury to the myocardium [10]. Extensive research has therefore been performed to identify cardiac conditioning strategies to overcome the detrimental and irreversible effects of reperfusion injury and to improve cardiac function after myocardial ischemia. The phenomenon of ischemic preconditioning (IPC) has been described over 30 years ago and demonstrated that application of brief episodes of cardiac ischemia and reperfusion reduced the size of a subsequent myocardial infarct [8]. This promising observation triggered the investigation of other approaches for cardiac conditioning, including ischemic postconditioning and remote ischemic conditioning (RIC) [3]. However, both IPC and ischemic postconditioning require direct intervention to the heart, whereas RIC applies short episodes of ischemia and reperfusion in a distant target organ such as the upper limb and therefore provides a noninvasive therapeutic strategy for protecting the heart against acute ischemia-reperfusion injury. RIC has been shown to reduce infarct size in animal models [9] and the recent randomized clinical trial of remote ischemic conditioning in STelevation myocardial infarction (RIC-STEMI) reported significantly improved clinical outcome in patients [2]. The molecular mechanisms underlying cardioprotection by RIC are complex and still not fully understood. It has been demonstrated that RIC involves activation of peripheral sensory nerves [6] and the interaction of inflammatory and humoral signaling

This article is a commentary to the original article https://doi.org/10.1007/ s00424-019-02314-y

Martina Krüger

martina.krueger@uni-duesseldorf.de

1 Department of Cardiovascular Physiology, Medical Faculty, Heinrich Heine-University Düsseldorf, Universitätsstr. 1, 22.03, 00, D-40225 Düsseldorf, Germany pathways resulting in a release of cardioprotective factors that circulate to target organs via the blood stream [5].

Although the identity of these cardioprotective factor(s) is still unknown, the fact that remote ischemic conditioning results in blood plasma that carries cardioprotective agents may have major implications for future treatment strategies. In the current study, Lieder et al. isolated plasma from mini-pigs with or without remote preconditioning (by repeated short hindlimb ischemia/reperfusion) and transferred isolated plasma to rat hearts perfused ex vivo before or after global ischemia. The study confirms that the cardioprotective factors are present in the plasma, can be transferred across species, and reduce infarct size. Moreover, it demonstrates for the first time that conditioned plasma is protective to the target organ even when applied during the reperfusion phase after the ischemic event (Lieder et al. in this issue).

Is remotely conditioned donor plasma soon to be administered by the incoming ambulance as a first-line therapy for patients with acute myocardial infarction? The idea is tempting, but until this can seriously be considered, several open questions remain to be addressed. The failure of other clinical trials to achieve an improved outcome after cardiac surgery by remote preconditioning demonstrated that the mechanisms of cardioprotection are highly complex and may be disturbed by many factors, including anesthesia [4, 7]. Comorbidities such as diabetes mellitus also impair RIC-induced cardioprotection possibly by disturbed signaling of sensory fibers, or impaired endogenous signaling cascades [1]. In view of these facts, identifying the molecular mechanisms responsible for RICinduced cardioprotection and unraveling the cross-talk of involved signaling cascades seems more important than ever. The current study by Lieder et al. showed that the transmitted humoral factors in the preconditioned pig plasma are equally protective when given before ischemia or during reperfusion and initiate signal transduction pathways that converge on STAT3 activation. Many questions remain open, but the finding that critical mechanisms of cardioprotection can be initialized before or after myocardial ischemia and are equally 
effective throughout reperfusion could ultimately take us a small step closer to understanding the origin and identity of the conditioning factor(s).

\section{References}

1. Ferdinandy P, Hausenloy DJ, Heusch G, Baxter GF, Schulz R (2014) Interaction of risk factors, comorbidities, and comedications with ischemia/reperfusion injury and cardioprotection by preconditioning, postconditioning, and remote conditioning. Pharmacol Rev 66(4):1142-1174. https://doi.org/10.1124/pr.113.008300

2. Gaspar A, Lourenço AP, Álvares Pereira M, Azevedo P, RonconAlbuquerque R Jr, Marques J, Leite-Moreira AF (2018) Randomized controlled trial of remote ischemic conditioning in ST-elevation myocardial infarction as adjuvant to primary angioplasty (RIC-STEMI). Basic Res Cardiol 113(3):14. https://doi.org/ 10.1007/s00395-018-0672-3

3. Hausenloy DJ, Barrabes JA, Bøtker HE, Davidson SM, Di Lisa F, Downey J, Engstrom T, Ferdinandy P, Carbrera-Fuentes HA, Heusch G, Ibanez B, Iliodromitis EK, Inserte J, Jennings R, Kalia N, Kharbanda R, Lecour S, Marber M, Miura T, Ovize M, PerezPinzon MA, Piper HM, Przyklenk K, Schmidt MR, Redington A, Ruiz-Meana M, Vilahur G, Vinten-Johansen J, Yellon DM, GarciaDorado D (2016) Ischaemic conditioning and targeting reperfusion injury: a 30 year voyage of discovery. Basic Res Cardiol 111(6):70. https://doi.org/10.1007/s00395-016-0588-8

4. Hausenloy DJ, Candilio L, Evans R, Ariti C, Jenkins DP, Kolvekar S, Knight R, Kunst G, Laing C, Nicholas J, Pepper J, Robertson S, Xenou M, Clayton T, Yellon DM, ERICCA Trial Investigators (2015) Remote ischemic preconditioning and outcomes of cardiac surgery. N Engl J Med 373(15):1408-1417. https://doi.org/10. 1056/NEJMoa1413534
5. Kleinbongard P, Skyschally A, Heusch G (2017) Cardioprotection by remote ischemic conditioning and its signal transduction. Pflugers Arch 469(2):159-181. https://doi.org/10.1007/s00424016-1922-6

6. Lieder HA, Kleinbongard P, Skyschally A, Hagelschuer H, Chilian WM, Heusch G (2018) Vago-splenic axis in signal transduction of remote ischemic preconditioning in pigs and rats. Circ Res 123: 1152-1163. https://doi.org/10.1161/CIRCRESAHA.118.313859

7. Meybohm P, Bein B, Brosteanu O, Cremer J, Gruenewald M, Stoppe C, Coburn M, Schaelte G, Böning A, Niemann B, Roesner J, Kletzin F, Strouhal U, Reyher C, LaufenbergFeldmann R, Ferner M, Brandes IF, Bauer M, Stehr SN, Kortgen A, Wittmann M, Baumgarten G, Meyer-Treschan T, Kienbaum P, Heringlake M, Schön J, Sander M, Treskatsch S, Smul T, Wolwender E, Schilling T, Fuernau G, Hasenclever D, Zacharowski K, RIPHeart Study Collaborators (2015) A multicenter Trial of remote ischemic preconditioning for heart surgery. $\mathrm{N}$ Eng1 J Med 373(15):1397-1407. https://doi.org/10.1056/ NEJMoa1413579

8. Murry CE, Jennings RB, Reimer KA (1986) Preconditioning with ischemia: a delay of lethal cell injury in ischemic myocardium. Circulation 74(5):1124-1136. https://doi.org/10.1161/01.cir.74.5. 1124

9. Skyschally A, Gent S, Amanakis G, Schulte C, Kleinbongard P, Heusch G (2015) Across-species transfer of protection by remote ischemic preconditioning with species-specific myocardial signal transduction by reperfusion injury salvage kinase and survival activating factor enhancement pathways. Circ Res 117(3):279-288. https://doi.org/10.1161/CIRCRESAHA.117.306878

10. Yellon DM, Hausenloy DJ (2007) Myocardial reperfusion injury. N Engl J Med 357:1121-1135. https://doi.org/10.1056/ NEJMra071667

Publisher's note Springer Nature remains neutral with regard to jurisdictional claims in published maps and institutional affiliations. 